\title{
The Chemistry of Vitamin $\mathbf{B}_{12}$ THE CO-ORDINATION OF BIOLOGICALLY IMPORTANT MOLECULES
}

\author{
By H. A. O. HILL, J. M PRATT,* R. G. THORP, B. WARD AND R. J. P. WILliams \\ Inorganic Chemistry Laboratory, University of Oxford, Oxford, OX $13 Q R U . K$.
}

(Received 27 May 1970)

The following equilibrium constants (given as $\log K$ in units of $\mathrm{M}^{-1}$ ) were determined for the substitution of co-ordinated $\mathrm{H}_{2} \mathrm{O}$ in aquocobalamin by glycine (bound through N) 5.8, cysteine (bound through $\mathrm{S}$ ) 6.0 or 8.3, depending on the value chosen for the $\mathrm{p} K$ of the thiol group, and phenolate 2.9. The spectrum of the phenolate cobalamin shows an additional intense absorption band at $468 \mathrm{~nm}$ with a molar extinction coefficient of $1.1 \times 10^{4}$, which is assigned to a charge transfer from the phenolate to the cobalt ion. Equilibrium constants have also been determined for the equilibria between adenylcobamide cyanide and $\mathrm{CN}^{-}, \mathrm{HO}^{-}$and $\mathrm{H}^{+}$, which show that the adenine is more easily displaced by $\mathrm{CN}^{-}$and $\mathrm{HO}^{-}$than is 5,6-dimethylbenziminazole in vitamin $B_{12}$, but can be protonated by acid while still remaining co-ordinated to the cobalt. It is shown that in the binding of corrinoids to proteins and polypeptides the formation of hydrogen bonds is far more important than co-ordination by the metal.

In previous papers we have determined the formation constants for the binding of a variety of ligands in the axial positions of cobalt(III) corrinoids and have studied the interaction between the ligands as shown by the effect of changing one ligand on the properties of the complex such as the u.v.-visible spectrum of the corrin ring, the proton magnetic resonance of $\mathrm{H}-10$ of the corrin ring, the stretching frequency of cyanide co-ordinated in the trans-position and the formation constants for ligand substitution in the transposition (for references see Firth, Hill, Pratt, Thorp \& Williams, 1968b, 1969; Firth, Hill, Pratt \& Thorp, 1968c). The aim of the present paper is (1) to extend the study to include more ligands of interest to the biochemistry of the corrinoids, and (2) to discuss the binding of corrinoids by polypeptides and proteins.

Equilibrium constants have already been reported for the substitution of co-ordinated $\mathrm{H}_{2} \mathrm{O}$, usually in aquocobalamin, by several amino acids (e.g. histidine) and ligands containing functional groups of the type present in amino acids (e.g. ammonia, acetate, imidazole) (for references see the Discussion section). We have now determined the equilibrium constants for the substitution of $\mathrm{H}_{2} \mathrm{O}$ in aquocobalamin by the phenolate anion, by glycine and by cysteine.

* Present address: Imperial Chemical Industries Ltd., Petrochemical and Polymer Laboratory, P.O. Box 11, The Heath, Runcorn, Cheshire, U.K.
Most naturally occurring corrinoids possess a nucleotide side chain terminating in a heterocyclic base, which is usually a purine or benziminazole derivative and can co-ordinate to the cobalt. Almost all previous work on the spectra and equilibria has been carried out on the cobalamins and cobinamides. Cobalamins, which include vitamin $B_{12}$ itself (cyanocobalamin), all contain the base $\mathbf{5 , 6}$ dimethylbenziminazole. The cobinamides, on the other hand, lack the nucleotide sidechain and this co-ordination position is usually occupied by $\mathrm{H}_{2} \mathrm{O}$; the best known is Factor $\mathrm{B}$ (cyanoaquocobinamide). There is, by contrast, no quantitative information on equilibria involving corrinoids that contain purines, even though compounds such as $\psi-\mathrm{B}_{12} \dagger$ and adenylcobamide coenzyme, both of which contain adenine, are important products of microbial biosynthesis. We have therefore studied the co-ordinating ability of adenosine in $\psi-\mathrm{B}_{12}$ and determined the equilibrium constants for reaction with $\mathrm{H}^{+}, \mathrm{HO}^{-}$and $\mathrm{CN}^{-}$.

\section{MATERIALS AND METHODS}

Samples of cyano- and aquo-cobalamin were kindly given by $\mathrm{Dr} \mathrm{L}$. Mervyn of Glaxo Laboratories Ltd., Greenford, Middx., U.K., and a sample of $\psi-B_{12}$ was kindly given by Professor $K$. Bernhauer, Stuttgart, W. Germany. A.R. reagents were used whenever possible $\left(\mathrm{HClO}_{4}, \mathrm{NaOH}, \mathrm{KCN}, \mathrm{K}_{2} \mathrm{HPO}_{4}\right.$, sodium acetate, phenol);

$\dagger$ Abbreviation: $\psi-B_{12}$, adenylcobamide cyanide. 
glycine, cysteine hydrochloride and quinol were reagent grade.

Equilibrium constants were determined spectrophotometrically in aqueous solution at room temperature (except for $\psi$ - $\mathrm{B}_{12}$ and $\mathrm{CN}^{-}$, where the solutions were thermostatically controlled at $20^{\circ} \mathrm{C}$ ). The nature of the ligands involved in each equilibrium is given below. These constants are stoicheiometric equilibrium constants, i.e. the terms in parentheses refer to concentrations under the experimental conditions and not to thermodynamic activities.

Spectra were recorded on either a Beckman DK 2 or a Unicam SP.700 spectrophotometer, with $1 \mathrm{~cm}$ quartz cells. Molar extinction coefficients are based on the value of $3.04 \times 10^{4}$ for the $\gamma$-band $(367 \mathrm{~nm})$ of dicyanocobalamin, into which other cobalamins can easily be converted (Hill, Pratt \& Williams, 1964).

In studying the equilibrium between $\psi-\mathrm{B}_{12}$ and acid, the $\mathrm{pH}$ of the solution in the spectrophotometer cell (approx. $2 \mathrm{ml}$ ) was measured with a Radiometer pH-meter and a Radiometer GK 264 combined electrode.

The electrophoresis of $\psi \cdot B_{12}$ with vitamin $B_{12}$ as standard was carried out in a modified Baird and Tatlock C6/5400 horizontal electrophoresis tank at $200 \mathrm{~V}$.

\section{RESULTS}

Aquocobalamin and glycine. Aquocobalamin reacts readily with glycine in approximately neutral solution, and isosbestic points are observed. The $\gamma$-band of the product is situated at $360 \mathrm{~nm}$. Since cobalamins containing $\mathrm{H}_{2} \mathrm{O}$ and $\mathrm{CH}_{3} \cdot \mathrm{CO}_{2}^{-}$have $\gamma$-bands at 350 and $352 \mathrm{~nm}$ respectively, whereas those containing nitrogenous bases have them at longer wavelength, e.g. $\mathrm{NH}_{3} 356 \mathrm{~nm}$, imidazole $358 \mathrm{~nm}$ and pyridine $360 \mathrm{~nm}$ (Firth et al. 1969), we conclude that glycine is co-ordinated through the nitrogen atom, i.e. as $-\mathrm{O}_{2} \mathrm{C} \cdot \mathrm{CH}_{2} \cdot \mathrm{NH}_{2} \rightarrow$ Co. The rate of equilibration is rather low under the conditions required to observe an equilibrium, and solutions of aquocobalamin in acetate buffer, pH5.5, were therefore allowed to come to equilibrium in the presence of $0 \mathrm{M}, 0.02 \mathrm{M}-, 0.20 \mathrm{M}$ - and $2.0 \mathrm{M}$-glycine. The degree of complex-formation in the second and third solutions (43 and $91 \%$ ) gave apparent equilibrium constants under the experimental conditions of 20 and 27. Allowance for the formation of acetatocobalamin (Firth et al. 1969) and use of the value of $\mathrm{p} K_{a}=9.7$ for the removal of the proton from glycine (Sillén \& Martell, 1964) gave the value for the equilibrium constant:

$$
K=\frac{\left[\mathrm{Co}-\mathrm{NH}_{2} \cdot \mathrm{CH}_{2} \cdot \mathrm{CO}_{2}^{-}\right]}{\left[\mathrm{Co}-\mathrm{OH}_{2}\right]\left[\mathrm{NH}_{2} \cdot \mathrm{CH}_{2} \cdot \mathrm{CO}_{2}^{-}\right]}
$$

of $\log K=5.8 \pm 0.2$.

Aquocobalamin and cysteine. The formation of a complex from aquocobalamin and cysteine has already been reported (Hill, Pratt \& Williams, 1962; Pratt, 1964; Alder, Medwick \& Poznanski,
1966). The cobalt(III) ion is reduced to cobalt(II) by cysteine in alkaline solution (Hill et al. 1962; Peel, 1963; Pratt, 1964), and the equilibrium has therefore been studied in faintly acid solution. The spectrum of the product is similar to that of thiosulphatocobalamin in having an 'atypical' spectrum, characterized by the occurrence of the $\gamma$-band at longer wavelength with considerably diminished intensity and the appearance of other bands of comparable intensity in the $300-350 \mathrm{~nm}$ region (Pratt \& Thorp, 1966); the comparable wavelengths (with molar extinction coefficients $\times 10^{-4}$ in parentheses) are: cysteinatocobalamin, 338 (1.52), 350 (shoulder) (1.35) and $371 \mathrm{~nm}(1.41)$; thiosulphatocobalamin, 330 (1.55), $353(1.49)$ and $367 \mathrm{~nm}(1.55)$. Adler et al. (1966) also found that similar 'atypical' spectra were shown by cobalamins containing ethanethiol, cysteine and GSH. One can therefore conclude that cysteine is co-ordinated through the sulphur atom. Wagner \& Bernhauer (1964) showed by electrophoresis that the GSH complex was uncharged at $\mathrm{pH} 2.5$, had one negative charge over the range $\mathrm{pH} \mathrm{4-7}$ and two negative charges at $\mathrm{pH} 11$. At $\mathrm{pH} \mathrm{4-7} \mathrm{the} \mathrm{co-ordinated} \mathrm{GSH} \mathrm{has} \mathrm{therefore} \mathrm{lost}$ two protons, presumably from the carboxylic acid and thiol groups. We assume that the thiol group of cysteine also becomes ionized on co-ordination to the cobalt. Solutions of aquocobalamin in acetate buffer, $\mathrm{pH} \mathrm{5.5,} \mathrm{were} \mathrm{allowed} \mathrm{to} \mathrm{come} \mathrm{to} \mathrm{equilibrium}$ in the presence of $0 \mathrm{M}-, 0.001 \mathrm{M}-, 0.002 \mathrm{M}-$ and $0.1 \mathrm{M}$ (excess)-cysteine. The degree of complex-formation in the second and third solutions (61 and $80 \%$ ) gave apparent equilibrium constants under the experimental conditions of $1.6 \times 10^{3}$ and $2.0 \times 10^{3}$ respectively. Cysteine shows two $\mathrm{p} K$ values in alkaline solution of approx. 8 and 10; there is, however, no agreement on which corresponds to the ionization of the thiol and which to that of the ammonium group (see the discussion by Wallenfels \& Streffer, 1966). After allowing for the formation of acetatocobalamin, use of the value $\mathrm{p} K_{a} 8.2$ for the ionization of the thiol group in cysteine leads to the value $\log K 6.0$ and of the value $\mathrm{p} K_{a} 10.5$ to $\log K 8.3$, where the equilibrium constant is :

$$
K=\frac{[\mathrm{Co}-\mathrm{SR}]}{\left[\mathrm{Co}-\mathrm{OH}_{2}\right]\left[\mathrm{RS}^{-}\right]}
$$

Aquocobalamin and phenol. Aquocobalamin reacts rapidly with phenol in mildly alkaline solution to give a new complex with a rather low equilibrium constant and an unusual spectrum. The $\mathrm{p} K_{a}$ of phenol is 10.0. The equilibrium constant was determined in phosphate buffer, $\mathrm{pH} 10.5$; at higher pH phenol undergoes oxidation to give coloured products. Since the formation constant is low and no end point could be obtained corresponding to $100 \%$ formation, the constant was calculated by 
the method of Lunn \& Morton (1952) and Newton \& Arcand (1953). No complex-formation was observed at $\mathrm{pH} 7$ and below, from which we conclude that the ligand is the phenolate anion. The equilibrium was shown to involve one phenol per cobalt and the formation constant found to be $K \mathbf{8 0 0}$ or $\log K 2.9$ where:

$$
K=\frac{\left[\mathrm{Co}-\mathrm{OC}_{6} \mathrm{H}_{5}\right]}{\left[\mathrm{Co}-\mathrm{OH}_{2}\right]\left[\mathrm{C}_{6} \mathrm{H}_{5} \mathrm{O}^{-}\right]}
$$

The spectrum of the fully formed phenolate complex was determined over the range $350-600 \mathrm{~nm}$ by extrapolation from mixtures with known ratios of the hydroxide and phenolate complexes. The $\alpha$ - and $\gamma$-bands of the phenolate $\left[\lambda_{\alpha} \quad 533 \mathrm{~nm}\right.$ (shoulder), $\epsilon_{M}$ approx. $0.93 \times 10^{4} ; \lambda_{\gamma} 355.5 \mathrm{~nm}$, $\epsilon_{M}$ approx. $\left.1.9 \times 10^{4}\right]$ are similar in energy and intensity to those of the hydroxide $\left(\lambda_{\alpha} 533 \mathrm{~nm}\right.$, $\left.\epsilon_{M} 0.92 \times 10^{4} ; \lambda_{\gamma} 356.5 \mathrm{~nm}, \epsilon_{M} 1.93 \times 10^{4}\right)$. But the phenolate also shows additional absorption in the region between the $\alpha$-and $\gamma$-bands with an apparent peak at $468 \mathrm{~nm}\left(\epsilon_{\mathrm{M}} 1.1 \times 10^{4}\right)$. If one assumes that this additional absorption is due to transitions of the charge-transfer type (see the Discussion section) and that the absorption due to the $\pi-\pi$ transitions alone would be the same as that of the hydroxide, then one can isolate the spectrum due to charge transfer alone by subtracting out the spectrum of hydroxocobalamin; this gives a very broad and featureless absorption extending from approx. 370 to approx. $530 \mathrm{~nm}$ with a flat maximum at approx. $455 \mathrm{~nm}$ with $\epsilon_{\mathrm{M}}$ approx. $0.7 \times 10^{4}$.

Yurkevich, Rudakova \& Pospelova (1966) have also reported the preparation of a complex from aquocobalamin and phenol that could be isolated as a solid. No equilibrium constant was reported and the phenol/cobalt ratio was not determined either for the solid or in solution. But the spectrum in aqueous solution showed an intense hand at $425 \mathrm{~nm}$ $\left(\epsilon 0.6 \times 10^{4}\right)$ in addition to the $\alpha-, \beta$ - and $\gamma$-bands at $540\left(0.6 \times 10^{4}\right), 510\left(0.6 \times 10^{4}\right)$ and $360 \mathrm{~nm}\left(2.8 \times 10^{4}\right)$. This complex could be the same as we have studied, although the low value of the equilibrium constant that we obtained makes it difficult to see how they obtained the spectrum of the apparently fully formed complex by dissolving the crystalline complex in water; in addition, the spectra are slightly different. They also reported that the spectrum of aquocobalamin was altered by the addition of quinol or resorcinol without stating whether a reaction or equilibrium was involved. In preliminary experiments we found that aquocobalamin reacted rapidly and irreversibly with quinol in alkaline solution to give products that absorb at about $400 \mathrm{~nm}$, i.e. quinol is involved in a reaction, not an equilibrium.

Equilibria involving $\psi-B_{12}$. The spectra of aqueous solutions of $\psi \cdot \mathrm{B}_{12}$ were studied over the range of $\mathrm{pHO}$ (1 M-perchloric acid) to 14.7 (5Msodium hydroxide). Reversible equilibria were observed in strongly alkaline and weakly acid solution. Electrophoresis at pH6 (0.05 M-phosphate buffer) confirmed that the complex possessed zero overall charge, as expected for adenylcobamide cyanide. At this $\mathrm{pH}$ the spectrum shows $\alpha-, \beta$ - and $\gamma$-bands at 546,516 and $359 \mathrm{~nm}$ respectively. The alkaline equilibrium was studied in solutions of 0-5 M-sodium hydroxide. Isosbestic points were observed, and from the position and relative heights of the absorption bands $(\alpha-, \beta$ - and $\gamma$-bands at 553,520 and $362 \mathrm{~nm}$ ) the axial ligands in the product were identified as $\mathrm{CN}^{-}$and $\mathrm{HO}^{-}$(cf. cyanohydroxocobinamide 550,525 and $362 \mathrm{~nm}$ ), i.e. adenine has been displaced by hydroxide. The equilibrium constant was determined from the point of inflexion of the graph of extinction at $359 \mathrm{~nm}$ against $\mathrm{HO}^{-}$ concentration; $\mathrm{p} K$ is 13.8 and $\log K$ is $0.2 \pm 0.2$, where:

$$
K=\frac{[\mathrm{NC}-\mathrm{Co}-\mathrm{OH}]}{[\mathrm{NC}-\mathrm{Co}-\mathrm{Ad}][\mathrm{OH}]}
$$

and Ad is the adenine of the nucleotide side chain. No analogous change was observed for cyanocobalamin (vitamin $B_{12}$ ) in solutions containing up to $2 \mathrm{M}$-sodium hydroxide, i.e. the corresponding $\log K$ is less than -0.5 .

The acid equilibrium was studied in solutions of $0-1 \mathrm{M}$-perchloric acid. The change in spectrum is relatively small, and the position of the $\alpha-, \beta$ - and $\gamma$-bands of the product $(541,513$ and $358 \mathrm{~nm})$ shows that the axial ligands are not $\mathrm{CN}^{-}$and $\mathrm{H}_{2} \mathrm{O}$ (cf. cyanoaquocobinamide 525,494 and $353 \mathrm{~nm}$ ), i.e. the adenine has not been displaced from co-ordination to the cobalt. Excellent isosbestic points were observed, and the plot of extinction at $359 \mathrm{~nm}$ against the $\mathrm{pH}$ of the solution, measured with a hydrogen electrode, gave $\mathrm{p} K 2.3 \pm 0.1$.

The reaction of $\psi-\mathrm{B}_{12}$ with potassium cyanide shows a simple equilibrium; good isosbestic points are observed and no further reaction is noted (for over $2 \mathrm{~h}$ ). The product has $\alpha-, \beta$ - and $\gamma$-bands at 579,540 and $368 \mathrm{~nm}$ (cf. dicyanocobinamide 580, 540 and $367 \mathrm{~nm}$ ). The equilibrium therefore involves one cyanide and the displacement of adenine from co-ordination by cyanide. The equilibrium constant was determined under the same conditions as those used previously for the analogous equilibrium of cyanocobalamin with cyanide, namely $20^{\circ} \mathrm{C}$, phosphate buffer, $\mathrm{pH} 11.4$, and low concentrations of potassium cyanide (Firth et al. 1969). Qualitative experiments indicated an equilibrium constant of approx. $10^{5}$. At the very low cyanide concentrations required by the high equilibrium constant, equilibrium is not established instantaneously. Solutions of $2.95 \mathrm{M}-\psi \cdot \mathrm{B}_{12}$ were therefore allowed to come to 
Table 1. Comparison of equilibria involving vitamin $\mathrm{B}_{12}$ and $\psi-\mathrm{B}_{12}$

\begin{tabular}{|c|c|c|c|c|c|}
\hline & Reagent & $\begin{array}{l}\text { Axial ligands } \\
\text { in product }\end{array}$ & Conditions & $\begin{array}{l}\log K \\
\left(\mathrm{M}^{-1}\right)\end{array}$ & Reference \\
\hline Vitamin $B_{12}$ & $\mathbf{H}^{+}$ & $\mathrm{NC}-\mathrm{Co}-\mathrm{OH}_{2}$ & $\mathrm{H}_{2} \mathrm{SO}_{4}-\mathrm{H}_{2} \mathrm{O}$ mixtures & $0.1 \pm 0.1$ & $\begin{array}{l}\text { Hayward, Hill, Pratt, } \\
\text { Vanston \& Williams } \\
\text { (1965) }\end{array}$ \\
\hline & $\begin{array}{l}\mathrm{HO}^{-} \\
\mathrm{CN}^{-}\end{array}$ & $\begin{array}{l}\mathrm{NC}-\mathrm{Co}-\mathrm{OH} \\
\mathrm{NC}-\mathrm{Co}-\mathrm{CN}\end{array}$ & $\begin{array}{l}\text { 0-2 } \mathrm{m}-\mathrm{NaOH} \\
\text { Phosphate buffer, } \\
\text { pH } 11.4 \text {, with } \\
\text { various KCN conens. }\end{array}$ & $\begin{array}{c}<-0.5 \\
3 \cdot 8 \pm 0 \cdot 2\end{array}$ & $\begin{array}{l}\text { This paper } \\
\text { Firth et al. }(1968 b)\end{array}$ \\
\hline$\psi \cdot \mathrm{B}_{12}$ & $\begin{array}{l}\mathrm{H}^{+} \\
\mathrm{HO}^{-} \\
\mathrm{CN}^{-}\end{array}$ & $\begin{array}{l}\mathrm{NC}-\mathrm{Co}-\mathrm{AdH}{ }^{*} \\
\mathrm{NC}-\mathrm{Co}-\mathrm{OH} \\
\mathrm{NC}-\mathrm{Co}-\mathrm{CN}\end{array}$ & $\begin{array}{l}0-1 \mathrm{M}-\mathrm{HClO}_{4} \\
0-5 \mathrm{~m}-\mathrm{NaOH} \\
\text { Phosphate buffer, } \\
\text { pH 11.4, with } \\
\text { various } \mathrm{KCN} \text { conens. }\end{array}$ & $\begin{array}{l}2.3 \pm 0.1 \\
0.2 \pm 0.2 \\
5.1 \pm 0.2\end{array}$ & $\begin{array}{l}\text { This paper } \\
\text { This paper } \\
\text { This paper }\end{array}$ \\
\hline
\end{tabular}

equilibrium $(30 \mathrm{~min})$ in the presence of $0.02 \mathrm{~mm}$ and $0.03 \mathrm{~mm}$-potassium cyanide. The following values of $K$, where:

$$
K=\frac{[\mathrm{NC}-\mathrm{Co}-\mathrm{CN}]}{[\mathrm{NC}-\mathrm{Co}-\mathrm{Ad}][\mathrm{CN}]}
$$

were obtained: $K 1.1 \times 10^{5}$ and $1.6 \times 10^{5}$ or $\log K 5.0$ and 5.2, i.e. $\log K 5.1 \pm 0.2$.

The above equilibrium constants involving $\psi-\mathbf{B}_{12}$ are given in Table 1 together with analogous data for cyanocobalamin.

\section{DISCUSSION}

Equilibrium constants of the cobalamins. All the cobalamins that have been prepared (both in the present work and previously) with amino acids or with ligands containing donor groups of the type present in amino acids have been listed in Table 2 with (1) the equilibrium constants $(\log K)$ where:

$$
K=\frac{[\mathrm{Co}-\mathrm{X}]}{\left[\mathrm{Co}-\mathrm{OH}_{2}\right][\mathrm{X}]}
$$

and (2) the apparent equilibrium constants at pH $7\left(\log K^{\prime}\right)$ where:

$$
K^{\prime}=\frac{[\mathrm{Co}-\mathrm{X}]}{\left[\mathrm{Co}-\mathrm{OH}_{2}\right]([\mathrm{X}]+[\mathrm{XH}])}
$$

The values of $K$ (or $K^{\prime}$ ) reported in the literature have been converted into $K^{\prime}$ (or $K$ ) by the use of the values of $\mathrm{p} K$ listed in column 2. Values of $K^{\prime}$ provide a measure of the strength of binding of amino acids and other ligands to the cobalt under physiological conditions. Certain qualitative observations on thiols and organic sulphides have also been included in Table 2. Adler et al. (1966) found no interaction between aquocobalamin and methionine, cystine or GSSG ; but no concentrations were reported and the maximum value of the equilibrium constant cannot therefore be calculated. Bauriedel (1956) states that of 20 (unspecified) common amino acids studied at $\mathrm{pH} 4.5$ only histidine reacted with aquocobalamin. Pyridine, imidazole and other imidazole-containing ligands such as histamine, carnosine and histidylhistidine in addition to histidine also reacted (Bauriedel, Picken \& Underkofler, 1956). Data are also included for $\mathrm{CN}^{-}$and $\mathrm{SO}_{3}{ }^{2-}$, which have the highest values of $K^{\prime}$ of all cobalamins so far studied; it is of note that these cobalamins are both produced as artifacts during the isolation of corrinoids. The identification of the ligand atom is discussed below under 'Spectra of the cobalamins'.

The data in Table 2 show that oxygen, nitrogen and sulphur atoms may all act as donors, though the equilibrium constants vary widely depending on the exact nature of the functional group; thus the values of $\log K^{\prime}$ for $\mathrm{S}$ are in $\mathrm{SO}_{3}{ }^{2-} 6.8$, in thiolates $3-5$ and in dialkylsulphides $<-1$. The following order of complexing ability is observed at $\mathrm{pH} 7$ with the donor groups present in amino acids: $\mathrm{N}$ (amine or imidazole) $\approx \mathrm{S}$ (thiolate) $\gg 0$ (carboxylate, phenolate). The very similar values of $K^{\prime}$ for amine, imidazole and thiolate mean that an amino acid or polypeptide with more than one of these functional groups can co-ordinate in more than one way, although one isomer will predominate; under certain conditions kinetic factors, such as the differing rates of co-ordination of amines and imidazoles, may play an important role.

Spectra of the cobalamins. A noticeable change in the spectrum accompanies the substitution of co-ordinated $\mathrm{H}_{2} \mathrm{O}$ by all the ligands listed in Table 2 with the exception of acetate. The $\gamma$-band shifts, but there is little change in the general shape of the absorption spectrum when a nitrogen atom is coordinated, whether in a base (ammonia, imidazole, 


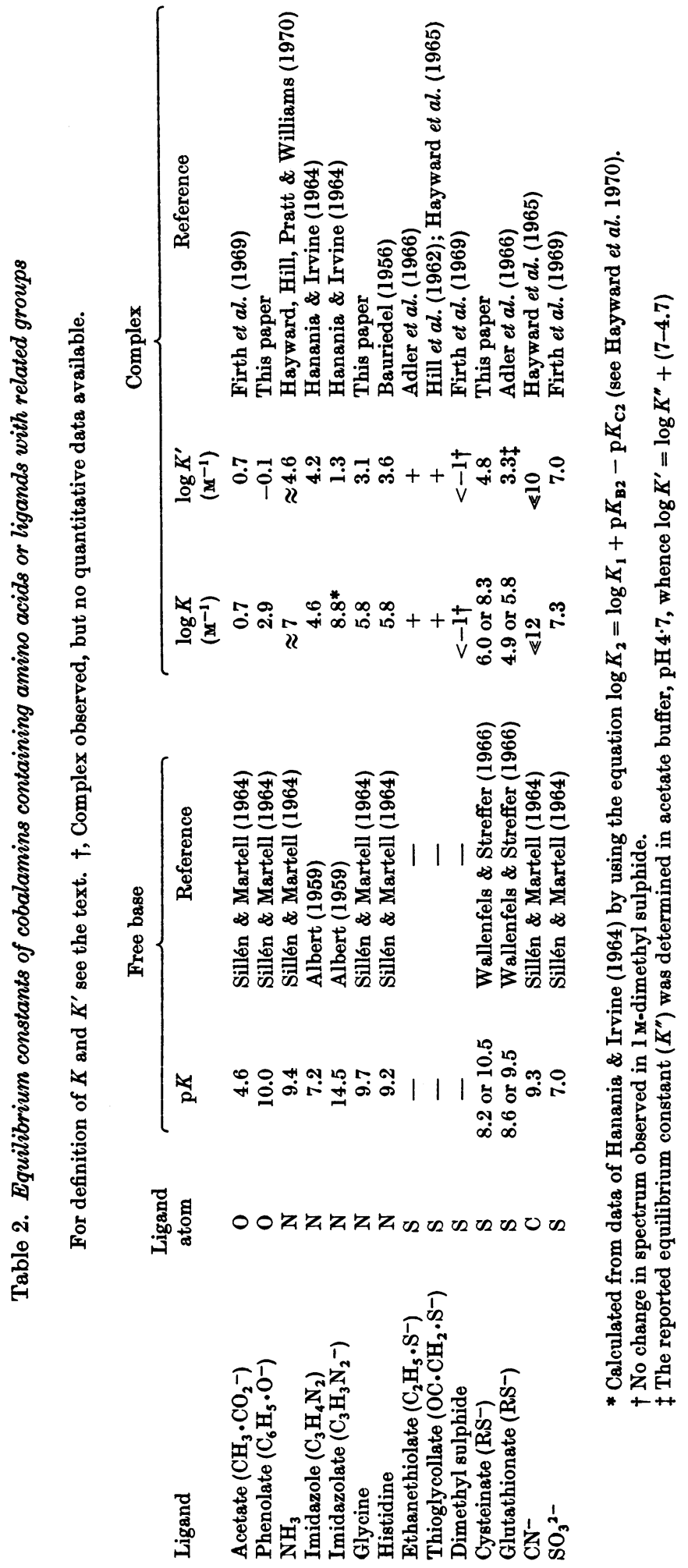


pyridine) or an anion $\left(\mathrm{N}_{3}^{-}, \mathrm{NCO}^{-}, \mathrm{NO}_{2}^{-}\right)$. $\mathrm{HO}^{-}$ causes a similar shift in wavelength, but the intensity of the $\gamma$-band is much lower, whereas phenolate produces a very unusual spectrum (see below). Ligands such as thiols, sulphite and thiosulphate (but not $\mathrm{NCS}^{-}$), which co-ordinate through a sulphur atom, all produce 'atypical' spectra, characterized by the presence of a $\gamma$-band at longer wavelength with low intensity and the appearance of new bands of comparable intensity in the region $300-350 \mathrm{~nm}$. Carbanions (as in 5,6-dimethylbenziminazolylcobamide coenzyme) and other very polarizable ligands such as $\mathrm{I}^{-}$and $\mathrm{NCSe}^{-}$also produce 'atypical' spectra. Further details of spectra are given by Pratt \& Thorp (1966) and Firth et al. (1969). It is therefore easy to detect the formation of a new complex as the result of the substitution of co-ordinated $\mathrm{H}_{2} \mathrm{O}$ and to identify the ligand atom (except in the case of carboxylates), e.g. whether cysteine and GSH are co-ordinated through oxygen, nitrogen or sulphur. It is much more difficult, however, to detect the substitution of 5,6-dimethylbenziminazole by another nitrogenous base or to decide whether histidine is coordinated through the imidazole or amine nitrogen atom. Since, however, histidine has a higher equilibrium constant at $\mathrm{pH} 7\left(\log K^{\prime} \quad 3.6\right)$ than glycine $\left(\log K^{\prime} 3.1\right)$ and histidine alone out of 20 amino acids tested reacted with aquocobalamin under the experimental conditions (Bauriedel, 1956), it seems reasonable to conclude that histidine is co-ordinated through the imidazole nitrogen atom.

The unusual spectrum of the phenolate complex deserves further comment. It clearly contains an additional intense band centred at about $455 \mathrm{~nm}$ that is superimposed on the normal pattern of $\alpha-, \beta$ - and $\gamma$-bands. Similar intense bands or unusual colours have been reported for complexes of various phenolates with silver(I) (see, e.g., Blanchard, Finkbeiner \& Russell, 1962), copper(II) (Blanchard et al. 1962; Harrod, 1969), titanium(IV) (Watenpaugh \& Caughlin, 1966) and iron(III) (Ackermann \& Hesse, 1969; Limb \& Robinson, 1969). The phenolatopenta-aquoiron(III) complex shows an intense band $(\epsilon 1200)$ at $560 \mathrm{~nm}$ (Ackermann \& Hesse, 1969). In all these complexes the metal ion is known to be readily reduced, whereas phenols are, of course, oxidizable, and the transitions giving rise to the intense absorption can be ascribed to a charge-transfer transition from the phenolate to the metal ion. Harrod (1969) did, however, conclude that charge transfer occurred from the copper(II) to the phenolate, but his arguments were based mainly on trends in thermal stability and cannot be accepted.

Co-ordination of adenine in $\psi-B_{12}$ and adenylcobamide coenzyme. The equilibrium constants presented in Table 1 are the first quantitative data relating to the co-ordination of the nucleotide adenine in $\psi-\mathrm{B}_{12}$. There are two main points of interest. First, comparison with the analogous equilibrium constants for vitamin $B_{12}$ (see Table 1) with $\mathrm{CN}^{-}$and $\mathrm{HO}^{-}$shows that the cobalt-adenine bond is about an order of magnitude weaker than the cobalt-5,6-dimethylbenziminazole bond. Secondly, $\psi-\mathrm{B}_{12}$ differs from vitamin $\mathrm{B}_{12}$ in its behaviour towards acid. Both bases can be protonated, but adenine remains co-ordinated whereas 5,6dimethylbenziminazole is displaced from the cobalt. Since substituted anilines usually have $\mathrm{p} K$ values in the range $1-5$, the co-ordinated adenine is probably protonated on the amino group. Heterocyclic bases can therefore co-ordinate to the cobalt ion of corrinoids in three forms: (1) as the neutral base, (2) in the anionic form, as shown for imidazolate, benziminazolate and adeninate anions (Hayward et al. 1970), and now (3) as a protonated base.

These results can be used to explain the structure and spectra of adenylcobamide coenzyme. Adenylcobamide coenzyme has the same spectrum at all $\mathrm{pH}$ values as 5,6-dimethylbenziminazolylcobamide coenzyme in acid solution (Bernhauer, Gaiser, Müller $\&$ Wagner, 1960), i.e. the adenine is not co-ordinated to the cobalt. This is clearly due to a combination of (i) the strong trans-weakening effect of the organo ligand together with (ii) the weakness of the cobaltadenine bond compared with the cobalt-5,6dimethylbenziminazole bond. For a fuller discussion of the trans-effect in relation to the equilibrium constants for ligand substitution in the corrinoids see Firth et al. $(1968 b, 1969)$ and Hayward et al. (1970). The indirect evidence adduced for five-co-ordination in the alkyl corrinoids (Firth et al. $1968 a$ ) can now be considered as supported by the $\mathrm{X}$-ray analysis of $N N^{\prime}$-ethylenebis(acetylacetoneiminato)methylcobalt(III), which shows the complex to be five-co-ordinate (Brückner, Calligaris, Nardin \& Randaccio, 1969). In 5,6-dimethylbenziminazolylcobamide coenzyme the cobalt-5,6dimethylbenziminazole bond is weakened to such an extent that the complex exists in aqueous solution as a mixture of about $90 \%$ of the expected six-co-ordinate complex and about $10 \%$ of the five-co-ordinate complex, in which 5-6,dimethylbenziminazole is no longer co-ordinated. By analogy with ethylcobinamide (Firth et al. 1968a) we can conclude that adenylcobamide coenzyme exists mainly as the five-co-ordinate complex. It has also been shown that the rate of interconversion of the five- and six-co-ordinate corrinoids is extremely rapid (Firth et al. 1968a). Since the formation constants for the binding of all ligands in the position trans to methyl, ethyl and 5-deoxyadenosyl are $\operatorname{low}(\log K 2$ or less), i.e. the cobalt ion in this environ- 
ment shows no strong preference for any particular type of ligand (Pailes \& Hogenkamp, 1968; Firth et al. 1969) and the rates of substitution are high, the cobalt ion is obviously open to attack by a wide range of potential ligands or substrates.

Binding of corrinoids to polypeptides and proteins. A complex of aquocobalamin with a polypeptide has been isolated and the composition of the 80 amino acid residues determined (Hedbom, 1960). The cobalamin is firmly held and the spectrum shows a $\gamma$-band at $350 \mathrm{~nm}$ (i.e. probably aquocobalamin). On treatment with cyanide the $\gamma$-band moves to $361 \mathrm{~nm}$ (i.e. cyanocobalamin) and the cobalamin is released from the complex. It is clear that the spectrum excludes the possibility of the co-ordination of any nitrogen or sulphur atom from an amino acid side chain. The co-ordination of a carboxylate group cannot be so firmly excluded, but in this case the formation constant at $\mathrm{pH} \mathrm{7,}$ $\log K^{\prime}$, is less than 1 . The firm binding of aquocobalamin to the polypeptide cannot therefore be explained by co-ordination of an amino acid to the cobalt. Similar arguments can be used to show that the binding of vitamin $B_{12}$ and 5,6-dimethylbenziminazolylcobamide coenzyme to various proteins can also not be due primarily to changes in the co-ordination sphere. Spectroscopic and other studies have shown that neither the cyanide nor the alkyl ligand is displaced on binding to the protein, and that if 5,6-dimethylbenziminazole is displaced it can only be displaced by a ligand that has an almost identical effect on the spectrum (see, e.g., Wijmenga, Thompson, Stern \& O'Connell, 1954; Gregory \& Holdsworth, 1955; Babior \& Li, 1969; Babior, Kon \& Lecar, 1969). Examination of the known equilibrium constants in solution shows that for the binding of either vitamin $B_{12}$ or 5,6-dimethylbenziminazolylcobamide coenzyme by the displacement of 5,6-dimethylbenziminazole by any amino acid functional group the formation constant will be less than 1. We conclude that the major factor in the binding of corrinoids to proteins or polypeptides is the formation of hydrogen bonds.

This work was supported by the Medical Research Council (U.K.). We thank Dr L. Mervyn and Glaxo Laboratories Ltd. for samples of cyano- and aquocobalamin, and Professor K. Bernhauer for a sample of adenylcobamide cyanide $\left(\psi-\mathrm{B}_{12}\right)$. This is paper no. 13 of the series 'The chemistry of vitamin $B_{12}$ ' [paper no. 12: Hayward et al. (1970)].

\section{REFERENCES}

Ackermann, G. \& Hesse, D. (1969). Z. anorg. allg. Chem. 367, 243.
Adler, N., Medwick, T. \& Poznanski, T. J. (1966). J. Am. chem. Soc. 88, 5018.

Albert, A. (1959). Heterocyclic Chemistry, p. 143. London: Athlone Press (University of London).

Babior, B. M., Kon, H. \& Lecar, H. (1969). Biochemistry, Easton, 8, 2662.

Babior, B. M. \& Li, T. K. (1969). Biochemistry, Easton, $8,154$.

Bauriedel, W. R. (1956). Iowa St. Coll. J. Sci. 30, 321.

Bauriedel, W. R., Picken, J. C. \& Underkofler, L. A. (1956). Proc. Soc. exp. Biol. Med. $91,377$.

Bernhauer, K., Gaiser, P., Müller, O. \& Wagner, O. (1960). Biochem. Z. 333, 106.

Blanchard, H. S., Finkbeiner, H. L. \& Russell, G. A. (1962). J. Polym. Sci. 58, 469.

Brückner, S., Calligaris, M., Nardin, G. \& Randaccio, L., (1969). Inorganica chim. Acta, 3, 308.

Firth, R. A., Hill, H. A. O., Mann, B. E., Pratt, J. M., Thorp, R. G. \& Williams, R. J. P. (1968a). J. chem. Soc. A, p. 2419.

Firth, R. A., Hill, H. A. O., Pratt, J. M. \& Thorp, R. G. (1968c). Analyt. Biochem. 23, 429.

Firth, R. A., Hill, H. A. O., Pratt, J. M., Thorp, R. G. \& Williams, R. J. P. (1968b). J. chem. Soc. A, p. 2428.

Firth, R. A. Hill, H. A. O., Pratt, J. M. Thorp, R. G. \& Williams R. J. P. (1969). J. chem. Soc. A, p. 381.

Gregory, M. E. \& Holdsworth, E. S. (1955). Biochem. J. 59, 335.

Hanania, G. I. H. \& Irvine, D. H. (1964). J. chem. Soc. p. 5694.

Harrod, J. F. (1969). Can. J. Chem. 47, 637.

Hayward, G. C., Hill, H. A. O., Pratt, J. M., Vanston, N. J. \& Williams, R. J. P. (1965). J. chem. Soc. p. 6485.

Hayward, G. C., Hill, H. A. O., Pratt, J. M. \& Williams, R. J. P. (1970). J. chem. Soc. A (in the Press).

Hedbom, A. (1960). Biochem. J. 74, 307.

Hill, J. A., Pratt, J. M. \& Williams, R. J. P. (1962). J. theor. Biol. 3, 423.

Hill, J. A., Pratt, J. M. \& Williams, R. J. P. (1964). J. chem. Soc. p. 5149.

Limb, G. \& Robinson, R. J. (1969). Analytica chim. Acta, 47, 451 .

Lunn, A. K. \& Morton, R. A. (1952). Analyst, Lond., 77, 718.

Newton, T. W. \& Arcand, G. M. (1953). J. Am. chem. Soc. 75, 2449.

Pailes, W. H. \& Hogenkamp, H. P. C. (1968). Biochemistry, Easton, 7, 4160.

Peel, J. L. (1963). Biochem. J. 88, 296.

Pratt, J. M. (1964). J. chem. Soc. p. 5154.

Pratt, J. M. \& Thorp, R. G. (1966). J. chem. Soc. A, p. 187.

Sillén, L. G. \& Martell, A. E. (1964). Spec. Publs chem. Soc. no. 17: Stability Constants of Metal Ion Complexes.

Wagner, F. \& Bernhauer, K. (1964). Ann. N.Y. Acad. Sci. $112,580$.

Wallenfels, K. \& Streffer, C. (1966). Biochem. Z. 346, 119. Watenpaugh, K. \& Caughlin, C. N. (1966). Inorg. Chem. 5, 1782.

Wijmenga, H. G., Thompson, K. W., Stern, K. G. \& O'Connell, D. J. (1954). Biochim. biophys. Acta, 13, 144.

Yurkevich, A. M., Rudakova, I. P. \& Pospelova, T. A. (1966). Zh. obshch. Khim. 36, 850. 